\title{
Adubação nitrogenada em cultivares de arroz de terras altas
}

\author{
Flávio Minto Boldieri ${ }^{1}$, Disnei Amélio Cazetta², Domingos Fornasieri Filho ${ }^{3}$
}

\section{RESUMO}

O objetivo deste trabalho foi avaliar a influência de diferentes doses de N em cobertura (0, 30, 60, 90 e 120 kg ha-1) sobre as características agronômicas de diferentes cultivares de arroz de terras altas (Caiapó, Primavera, Confiança, IAC 202 e Carisma) sob irrigação por aspersão durante os anos agrícolas 2003/04 e 2004/05, em área experimental da FCAV - UNESP - Jaboticabal (SP). Os cultivares Caiapó, IAC 202 e Carisma são os de maior produtividade, com o Primavera não respondendo ao incremento da adubação nitrogenada; o IAC 202 e Carisma são possuidores de índice de colheita mais elevado e responsivos ao nitrogênio aplicado em cobertura, sugerindo-se indicá-los para sistemas produtivos mais evoluídos; o cultivar Caiapó demonstra ser mais eficiente em absorver e utilizar o N contido no solo, sugerindo sua indicação para sistemas produtivos de menor aporte de tecnologia.

Palavras-chave: Oryza sativa L., componentes de produção, eficiência agronômica.

\section{ABSTRACT}

\section{Nitrogen fertilization for sprinkler-irrigated upland rice cultivars}

This work was developed during the agricultural years 2003/04 and 2004/05, in the experimental area of the São Paulo State University (Unesp - FCAV), in Jaboticabal (SP). The objective of this work was to evaluate the influence of different $\mathrm{N}$ rates in side dressing $\left(0,30,60,90\right.$ and $\left.120 \mathrm{~kg} \mathrm{ha}^{-1}\right)$ on agronomic characteristics of different cultivars of upland rice (Caiapó, Primavera, Confiança, IAC 202 and Carisma), with sprinkler-irrigation. The cultivars Caiapó, IAC 202 and Carisma showed the highest yields, while Primavera did not respond to the increase in nitrogen fertilization; IAC 202 and Carisma had the highest harvest rates and were responsive to sidedressed nitrogen application and can be indicated for more advanced production systems; cultivatr Caiapó was shown to be more efficient in absorbing and using the $\mathrm{N}$ in the soil and can be indicated for production systems with lower technology input.

Key words: Agronomic efficiency, Oryza sativa L., yield components.

\footnotetext{
Recebido para publicação em abril de 2008 e aprovado em dezembro de 2009

${ }^{1}$ Engenheiro-Agrônomo. Departamento de Produção Vegetal da Faculdade de Ciências Agrárias e Veterinária - Universidade Estadual Paulista (FCAV-UNESP), Via de acesso Prof. Paulo Donato Castellane s/n, 14884-900, Jaboticabal, SP, Brasil. fmboldieri@yahoo.com.br

${ }^{2}$ Engenheiro-Agrônomo, Doutorando. Departamento de Produção Vegetal da Faculdade de Ciências Agrárias e Veterinária - Universidade Estadual Paulista (FCAV-UNESP), Via de acesso Prof. Paulo Donato Castellane s/n, 14884-900, Jaboticabal, SP, Brasil. edisnei@fcav.unesp.br

${ }^{3}$ Engenheiro-Agrônomo, Doutor. Departamento de Produção Vegetal da Faculdade de Ciências Agrárias e Veterinária - Universidade Estadual Paulista (FCAV-UNESP), Via de acesso Prof. Paulo Donato Castellane s/n, 14884-900, Jaboticabal, SP, Brasil. fornasieri@fcav.unesp.br
} 


\section{INTRODUÇÃO}

Para viabilizar a cultura de arroz de terras altas com irrigação suplementar, devem-se utilizar cultivares apropriados, pois os tradicionais normalmente apresentam grande desenvolvimento vegetativo, com abundância de folhas e porte alto, que favorecem o acamamento quando irrigados por aspersão (Stone \& Pinheiro, 1998; Fornasieri Filho \& Fornasieri, 2006). Já os cultivares modernos de arroz irrigados por inundação, de porte baixo, não se adaptam às condições físico-químicas dos solos bem drenados e mostram alta suscetibilidade às doenças e, nessas condições, apresentam baixa produtividade (Stone \& Pinheiro, 1998; Fornasieri Filho \& Fornasieri, 2006). Outro aspecto a ser considerado como limitante à produção de arroz é o manejo da adubação nitrogenada, a qual influi na intensidade dos efeitos da deficiência hídrica na cultura do arroz, pois o fornecimento de doses crescentes de nitrogênio provoca mudanças nas características morfológicas e fisiológicas do arroz, o que influi na produtividade (Arf et al., 1996).

A produtividade de grãos é característica controlada por grande número de genes, sendo, portanto, herança quantitativa. Isso ocorre porque a produtividade de grãos depende da interação de vários componentes de produção e do ambiente, mostrando que as correlações entre a produtividade de grãos e seus componentes podem ter valores significativos, positivos ou negativos (Fageria et al., 2007). Assim, o conhecimento dessas correlações com o meio pode ajudar os melhoristas na seleção de novos cultivares, pois encontram-se na literatura resultados muito variáveis quanto aos componentes de produção e produtividade de cultivares de uma região para outra, ainda mais quando se envolve nesses estudos a utilização de doses de nitrogênio em cobertura, como verificado em Donald \& Hamblim (1976), Fageria \& Barbosa Filho (1982), Andrade et al. (1992), Arf el al. (1996), Stone et al. (1999), Freitas et al. (2001), Fageria \& Baligar (2006), Arf et al. (2002), Gimarães \& Stone (2003), Mauad el al. (2003), Arf et al. (2003), Jiang et al. (2004), Buzetti et al. (2006), Freitas et al. (2007) e Fageria et al. (2007).

O nitrogênio é parte constituinte das proteínas, que, por sua vez, são componentes dos cloroplastos, enzimas e protoplasma. Em relação aos componentes de produção de grãos, esses podem ser afetados pela nutrição (Freitas et al., 2001). O desenvolvimento desses componentes pode ser influenciado positivamente pelo nitrogênio, devido às múltiplas funções deste nutriente na planta (Fageria \& Barbosa Filho, 1982). De acordo com Fornasieri Filho \& Fornasieri (2006), o nitrogênio é, entre os macronutrientes, o segundo mais exigido pela cultura do arroz e o mais exportado como produto colhido. Em média, para a produção de uma tonelada de grãos são absorvidos 27 kg de N por genótipo de arroz de sequeiro tradicional (Fageria et al., 1995a) e $32 \mathrm{~kg}$ de $\mathrm{N}$ por genótipo de arroz de sequeiro favorecido (Fageria et al., 1995b); e a utilização do N também pode causar prejuízos ambientais, por apresentar elevado custo energético para sua produção e ser passível de contaminação de águas superficiais e subterrâneas por nitrato, em virtude de perdas por erosão e lixiviação (Sims et al., 1998) e/ou volatilização (Lara Cabezas et al., 1997). Assim, para a recomendação de adubação nitrogenada é necessário definir a utilização de doses e épocas de aplicação mais adequadas de forma a maximizar os retornos econômicos com a aplicação de nitrogênio e minimizar os riscos de poluição ambiental, em especial na água subterrânea.

O objetivo do presente trabalho foi avaliar o comportamento de cultivares de arroz de terras altas, quando submetidas a diferentes doses de nitrogênio em cobertura, sob condição de irrigação suplementar por aspersão em Jaboticabal, SP, nos anos agrícolas 2003/04 e 2004/05.

\section{MATERIAL E MÉTODOS}

O experimento foi desenvolvido em área agrícola da Faculdade de Ciências Agrárias e Veterinárias da Universidade Estadual Paulista, Campus de Jaboticabal, localizada a $21^{\circ} 14^{\prime} 05^{\prime \prime}$ S, na longitude de $48^{\circ} 17^{\prime} 09^{\prime \prime} \mathrm{W}$, a uma altitude de 615 m, em um Latossolo Vermelho-Eutrófico de textura argilosa. O clima da região, segundo a classificação de Köeppen, é considerado como zona de transição entre as regiões de clima Cwa (clima mesotérmico/tropical de altitude) e Aw (clima megatérmico/tropical úmido), com chuvas no verão e inverno relativamente seco.

O sistema de preparo de solo empregado nos dois anos de cultivo foi o convencional, mediante a utilização de aração seguida de duas gradagens, tendo a primeira finalidade de eliminação dos torrões e uniformização do terreno, e, a segunda, feita pouco antes da semeadura, para o nivelamento do solo e eliminação de sementeiras de plantas daninhas. Previamente ao preparo do solo no primeiro ano, foram coletadas amostras de solo deformadas da área experimental na profundidade de 0-20 cm e realizada a análise química de acordo com o método proposto por Raij \& Quaggio (1983), obtendo-se os seguintes resultados: $\mathrm{pH}\left(\mathrm{CaCl}_{2}\right)=5,6$; M.O. $=29 \mathrm{~g} \mathrm{dm}^{-3}$; $\mathrm{P}($ resina $)$ $=42 \mathrm{mg} \mathrm{dm}^{-3} ; 4,4 ; 47 ; 19 ; 28 ; 70,4 ; 98,4$ mmol $_{\mathrm{c}} \mathrm{dm}^{-3} \mathrm{de} \mathrm{K}$, $\mathrm{Ca}, \mathrm{Mg}, \mathrm{H}+\mathrm{Al}$, SB e CTC, respectivamente, e $72 \%$ de saturação por bases.

O arroz foi semeado em 12/11/2003 e 12/12/2004 com auxílio de uma semeadora mecânica, em linhas espaçadas entre si de $40 \mathrm{~cm}$, sendo conjuntamente realizada a aplicação de fertilizante mineral, na quantidade de $300 \mathrm{~kg} \mathrm{ha}^{-1} \mathrm{de}$ 04-20-20, de acordo com as recomendações sugeridas por Cantarella \& Furlani (1997) para uma produtividade esperada de $3,0 \mathrm{t} \mathrm{ha}^{-1}$. 
O delineamento experimental utilizado foi o de blocos casualizados, com quatro repetições. Os tratamentos foram dispostos num esquema fatorial $5 \times 5$, representados por cultivares de arroz (Caiapó, Primavera, Confiança, IAC 202 e Carisma) e doses de nitrogênio em cobertura $\left(0,30,60\right.$, 90 e $\left.120 \mathrm{~kg} \mathrm{ha}^{-1}\right)$. As parcelas constituíram-se de 10 linhas com seis metros de comprimento, mantendo-se entre uma parcela e outra uma distância de um metro. Como área útil foram consideradas as seis linhas centrais com cinco metros de comprimento. A densidade de semeadura foi de 200 sementes viáveis $/ \mathrm{m}^{2}$. A adubação nitrogenada de cobertura foi realizada no estádio de "ponto algodão” na forma de nitrato de amônio, nas respectivas parcelas.

O controle das plantas daninhas, nos dois anos de cultivo, foi realizado no estádio de pré-emergência da cultura, com a utilização do produto à base de pendimethalin, na dose de 1.500 g i.a. ha-1 $\left(3,0 \mathrm{~L} \mathrm{ha}^{-1}\right.$ p.c.), e aos 20 dias após a emergência foi utilizado produto à base de fenoxaprop-p-ethyl, na dose de $50 \mathrm{~g}$ i.a. ha-1 (0,7 L ha-1 p.c.).

Durante os períodos experimentais foram analisados: a) número de panículas por área, determinado pela contagem do número de panículas em dois metros lineares na área útil de cada unidade experimental, transformando-se os valores obtidos para $\mathrm{m}^{2}$; b) número de espiguetas por panícula, pela contagem do número de espiguetas em 10 panículas escolhidas ao acaso na área útil de cada unidade experimental; c) número de grãos por panícula, realizado após a contagem do número de espiguetas, quando elas foram colocadas em um recipiente contendo água, sendo o material que afundou (espiguetas férteis) considerado como grão; d) fertilidade das espiguetas, realizada pela relação entre o número de grãos por panícula pelo número de espiguetas totais; e) massa de 100 grãos, determinada pela pesagem de duas amostras de 100 grãos em cada unidade experimental, fazendo-se a média e corrigindo-se a umidade para 13\% base úmida; f) produtividade de grãos, determinada após a colheita seguida de trilha, abanação e secagem do produto coletado nas linhas da área útil de cada unidade experimental e, em seguida, realizada a pesagem com subsequente transformação dos dados em $\mathrm{kg} \mathrm{ha}^{-1}$ (com correção da umidade a 13\% base úmida); g) índice de colheita (IC), calculado pela relação entre o peso de grãos pelo peso da fitomassa seca total (menos raízes), sendo expresso em percentagem; e h) eficiência agronômica do uso do N (EA), estimada pela expressão $E A=\left(P_{N}-P G_{T}\right) / Q_{a}$, em que $P_{N}$ e $P G_{T}$ representam a produtividade média de grãos na presença e na ausência de $\mathrm{N}$, respectivamente, e $\mathrm{QN}_{\mathrm{a}}$ a quantidade de $\mathrm{N}$ aplicado, que reflete no incremento de produção em kg de grãos obtido por kg de $\mathrm{N}$ aplicado (kg grãos/kg $\mathrm{N}$ ).
Os dados obtidos foram submetidos à análise de variância (teste F), e quando alcançada significância estatística as médias foram comparadas pelo teste de Tukey a 5\% de probabilidade e, em seguida, foi realizada a análise de regressão para as doses de $\mathrm{N}$ e para as interações entre cultivares $\mathrm{x}$ doses de $\mathrm{N}$ em cobertura das diversas características avaliadas, quando significativas.

\section{RESULTADOS E DISCUSSÃO}

Observando o número de panículas por $\mathrm{m}^{2}$, verifica-se interação entre cultivares e doses de $\mathrm{N}$ nas duas safras agrícolas (Tabela 1). O cultivar Carisma, em ambas as safras, apresentou o maior número de panículas por área, independentemente da dose de $\mathrm{N}$ utilizada, respondendo de forma linear e positiva ao fornecimento do nutriente, similarmente ao observado com Primavera, IAC 202, Caiapó e Confiança na safra 2003/04 (Figura 1a) e com o Primavera na safra 2004/05 (Figura 1b); entretanto, esse componente foi maximizado no segundo ano agrícola, nos cultivares IAC 202, Caiapó e Confiança (Figura 1b). Stone et al. (1999) e Guimarães \& Stone (2003) também observaram aumento do número de panículas por área com o aumento da adubação nitrogenada em cobertura. O efeito diferencial observado entre os cultivares foi também relatado por Fageria \& Baligar (2001), sendo esse componente uma característica definida geneticamente e influenciada por fatores ambientais, no caso a aplicação de dose adequada de $\mathrm{N}$.

Quanto ao número de espiguetas por panícula, observa-se que o aumento das doses de $\mathrm{N}$ possibilitou acréscimos nesse componente em todos os cultivares (Figuras 1c e 1d), com destaque para o IAC 202 e Primavera na safra 2003/04 (Figura 1c) e por IAC 202 e Caiapó na safra 2004/05 (Figura 1d), corroborando com os resultados de Freitas et al. (2001); entretanto, Guimarães \& Stone (2003) não verificaram influência da adubação nitrogenada no número de espiguetas por panícula em cultivares de arroz de terras altas.

Para a fertilidade de espiguetas, o cultivar Confiança, na safra 2003/04, apresentou, independentemente da dose de $\mathrm{N}$, a maior fertilidade, ocorrendo ligeiro aumento na esterilidade com o aumento na dose de $\mathrm{N}$ fornecido; por sua vez, os cultivares IAC 202 e Carisma, embora tenham apresentado incremento linear nesse componente com a adubação nitrogenada, não atingiram os índices de fertilidade obtidos por Confiança (Figura 2a). Na safra 2004/05, o incremento na adubação nitrogenada proporcionou uma redução na fertilidade das espiguetas, exceto no Caiapó, tendo o grau de esterilidade variado de cultivar para cultivar, com Carisma e IAC 202 se destacando com as maiores fertilidades de espiguetas (Figura 2 b). Essas reduções na fertilidade de espiguetas na segunda safra podem 
Tabela 1. Valores médios referentes a número de panículas por área, número de espiguetas por panícula e fertilidade de espiguetas em diferentes cultivares de arroz submetidos à adubação nitrogenada em cobertura

\begin{tabular}{|c|c|c|c|c|c|c|}
\hline & \multicolumn{2}{|c|}{ Panículas por $\mathbf{m}^{2}$} & \multicolumn{2}{|c|}{$\mathrm{N}^{0}$ espiguetas por panícula } & \multicolumn{2}{|c|}{ Fertilidade de espiguetas (\%) } \\
\hline & $2003 / 2004$ & $2004 / 2005$ & $2003 / 2004$ & $2004 / 2005$ & $2003 / 2004$ & $2004 / 2005$ \\
\hline & \multicolumn{6}{|c|}{ Cultivar (C) } \\
\hline Primavera & 153 e & $150 \mathrm{~cd}$ & $229 \mathrm{~b}$ & $149 \mathrm{c}$ & $71 \mathrm{~b}$ & $67 \mathrm{~b}$ \\
\hline Carisma & $248 \mathrm{a}$ & 239 a & 163 c & $151 \mathrm{c}$ & 65 c & $80 \mathrm{a}$ \\
\hline IAC 202 & $163 \mathrm{~d}$ & $145 \mathrm{~d}$ & $258 \mathrm{a}$ & $205 \mathrm{a}$ & $66 c$ & $78 \mathrm{a}$ \\
\hline Caiapó & $199 \mathrm{~b}$ & $182 \mathrm{~b}$ & 162 c & $180 \mathrm{~b}$ & $75 \mathrm{a}$ & $78 \mathrm{a}$ \\
\hline Confiança & 184 c & $156 c$ & 164 c & $134 \mathrm{~d}$ & $74 \mathrm{a}$ & $68 \mathrm{~b}$ \\
\hline Teste F - Cult. (C) & $1066,10^{* *}$ & $380,33^{* *}$ & $126,8^{* *}$ & $201,19^{* *}$ & $51,15^{* *}$ & $53,59^{* *}$ \\
\hline \multirow{2}{*}{ D.M.S. (Tukey 5\%) } & 4,52 & 7,87 & 15,90 & 7,98 & 2,57 & 3,21 \\
\hline & & & \multicolumn{2}{|c|}{ Doses de N (kg ha $\left.{ }^{-1}\right)$} & & \\
\hline 0 & 162 & 140 & 162 & 137 & 69 & 78 \\
\hline 30 & 178 & 164 & 187 & 152 & 68 & 76 \\
\hline 60 & 191 & 180 & 203 & 168 & 70 & 73 \\
\hline 90 & 199 & 186 & 209 & 173 & 72 & 73 \\
\hline 120 & 218 & 201 & 214 & 190 & 71 & 71 \\
\hline Teste F - Doses N (D) & $347,72^{* *}$ & $135,75^{* *}$ & $27,77^{* *}$ & $103,13^{* *}$ & $5,89^{* *}$ & $10,16^{* *}$ \\
\hline Teste F (Int. C x D) & $48,47^{* *}$ & $7,36^{* *}$ & $2,16^{*}$ & $3,52^{* *}$ & 3,96 ** & $3,58^{* *}$ \\
\hline C.V.\% & 2,69 & 5,10 & 9,19 & 5,50 & 4,11 & 4,89 \\
\hline
\end{tabular}

Médias seguidas da mesma letra na coluna não diferem entre si, pelo teste de Tukey, a 5\% de probabilidade.

** e $*$ = significativo a $1 \%$ e $5 \%$ de probabilidade pelo teste $\mathrm{F}$, respectivamente; NS = não-significativo.
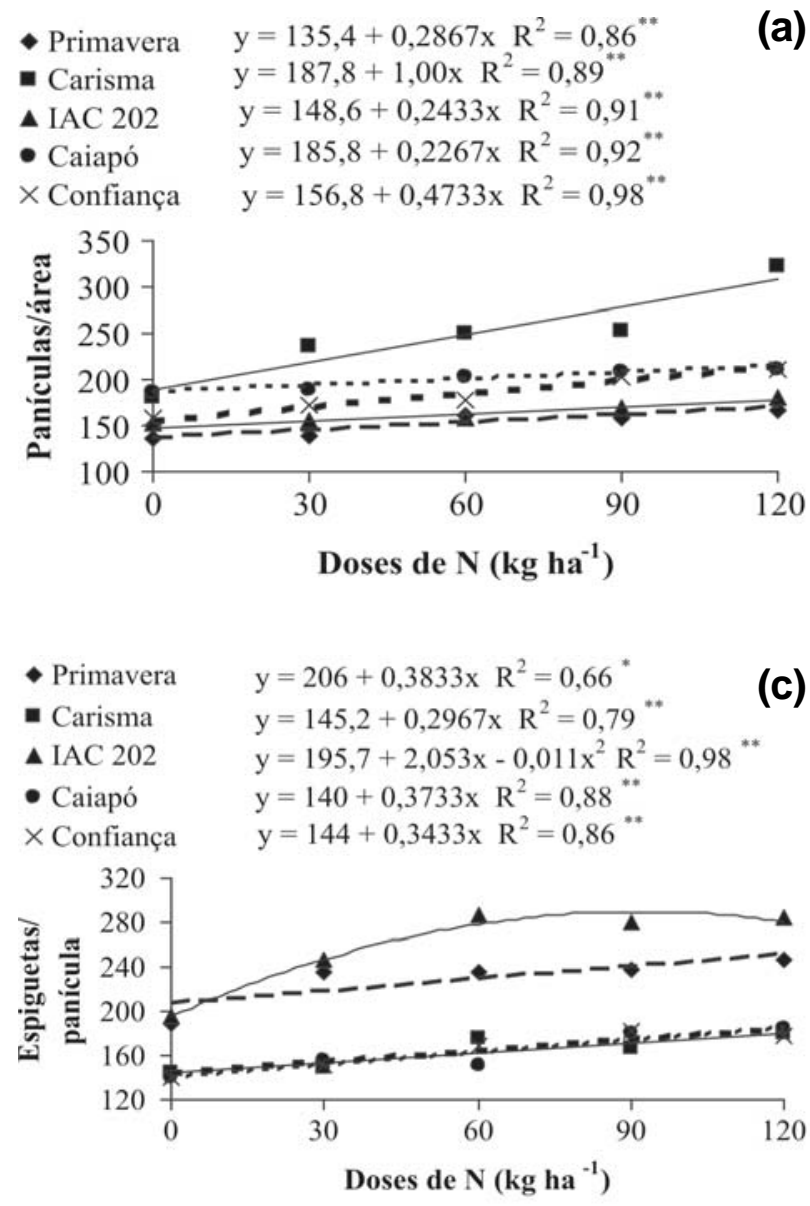

Figura 1. Efeito da interação entre os cultivares e as doses de nit ogênio em relação ao número de panículas por área (Figuras 1a safra 2003/04 e 1b - safra 2004/05) e espiguetas por panículas (Figuras 1c - safra 2003/04 e 1d - safra 2004/05).

(b)

$$
\begin{array}{ll}
\text { - Carisma } & \mathrm{y}=190,94+0,798 \mathrm{x} \mathrm{R}^{2}=0,88{ }^{* *} \\
\text { - IAC 202 } & \mathrm{y}=118,64+0,7519 \mathrm{x}-0,0035 \mathrm{x}^{2} \mathrm{R}^{2}=0,999^{* *} \\
\text { - Caiapó } & \mathrm{y}=145,57+1,021 \mathrm{x}-0,0046 \mathrm{x}^{2} \mathrm{R}^{2}=0,99 \\
\times \text { Confiança } & \mathrm{y}=132,67+0,1086 \mathrm{x}+0,0031 \mathrm{x}^{2} \mathrm{R}^{2}=1,00
\end{array}
$$$$
\text { era } y=131,42+0,3077 x \quad R^{2}=0,94
$$
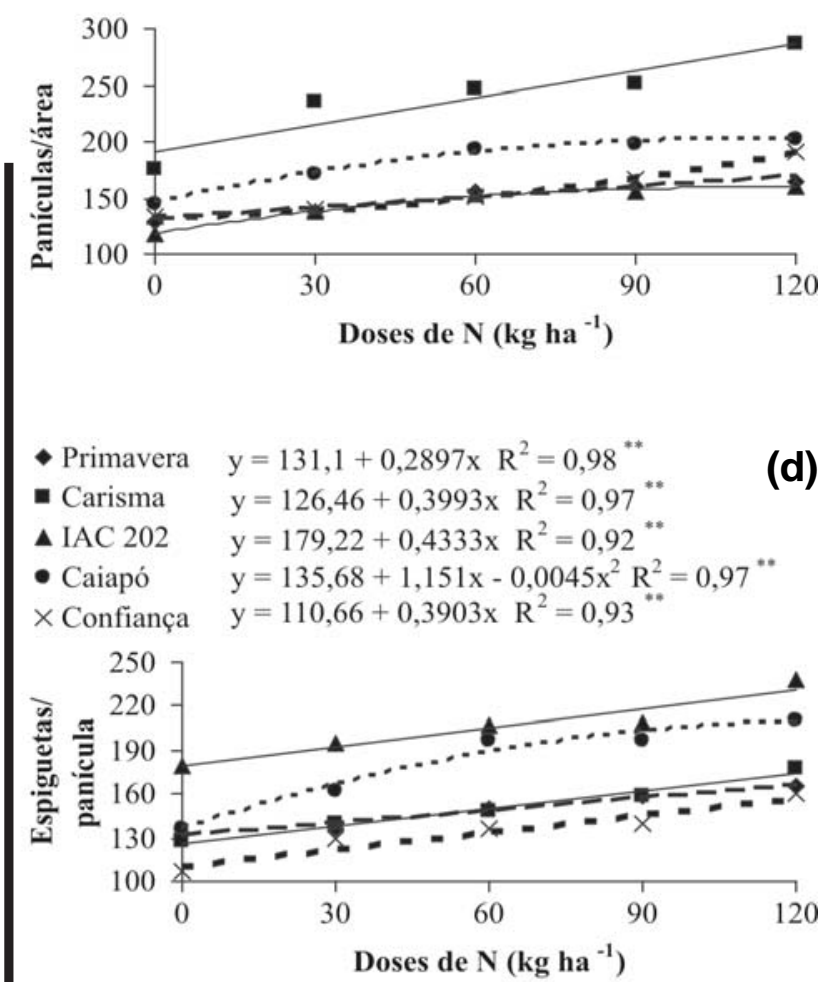

(d)

Rev. Ceres, Viçosa, v. 57, n.3, p. 421-428, mai/jun, 2010 

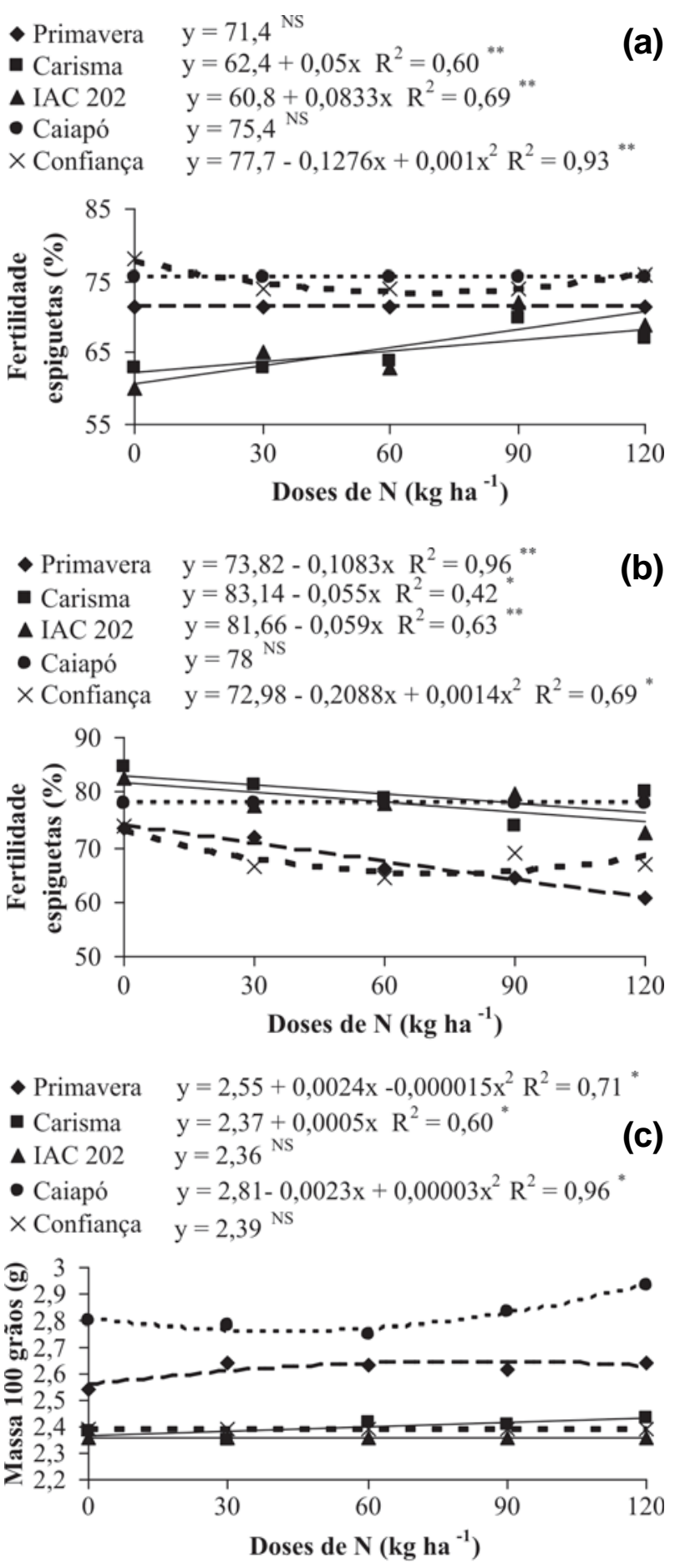

Figura 2. Efeito da interação entre os cultivares e as doses de nitrogênio em relação à fertilidade de espiguetas (Figuras 2a safra 2003/04 e 2b - safra 2004/05) e massa de 100 grãos (Figura 2c - safra 2004/05).

ser explicadas pelo incremento no número de panículas por área no cultivar Carisma (Figuras 1a e 1b) e no número de espiguetas por panícula na IAC 202 (Figura 1d) com a elevação das doses de $\mathrm{N}$ em cobertura, fazendo com que ocorresse maior competição desse nutriente no decorrer do processo de microsporogênese e de fecundação (Fornasieri Filho \& Fornasieri, 2006). Esse resultado per- mite verificar que a ocorrência de reduzida esterilidade sob altas doses de N é um critério importante na seleção de genótipos de arroz responsivos à aplicação de $\mathrm{N}$.

Quanto à massa de 100 grãos na safra 2003/04, essa foi influenciada somente pelos genótipos e variou de 2,35 a 2,78 (Tabela 2). Segundo Fornasieri Filho \& Fornasieri (2006), a massa de 100 grãos é uma característica varietal estável, por ser basicamente dependente do tamanho da casca. Também Andrade et al. (1992) e Fageria et al. (2007) não observaram a influência da adubação nitrogenada nesse componente. Na safra 2004/05 verificou-se interação entre cultivares e doses de N, com os cultivares Caiapó, Carisma e Primavera respondendo à fertilização nitrogenada de forma diferenciada (Figura 2c), o que não ocorre com IAC 202 e Confiança. Guimarães \& Stone (2003), Mauad et al. (2003) e Buzetti et al (2006) verificaram redução da massa de 100 grãos com o aumento da dose de N; Stone et al. (1999) e Arf et al. (2003) não contataram qualquer influência do $\mathrm{N}$ nesse componente. Os resultados aparentemente contraditórios observados e os relatados provavelmente decorram de essa característica ser dependente da densidade do grão. Assim, um cultivar com estande menor e/ou baixo índice de fertilidade de espigueta pode responder de forma diferenciada à adubação nitrogenada, possibilitando a influência na massa unitária do grão.

Quanto à produtividade de grãos (Tabela 2), verificase interação entre cultivares e doses de nitrogênio. Na safra 2003/04, os cultivares Carisma e IAC 202 apresentaram as maiores produtividades com Carisma, Primavera e Confiança, respondendo de forma crescente à adubação nitrogenada, obtendo-se na IAC 202 a maior produtividade com a dose de $105 \mathrm{~kg} \mathrm{ha}^{-1}$ de N. O Caiapó, apesar de apresentar, em média, as maiores produtividades de grãos (Tabela 2), não respondeu à adubação nitrogenada (Figura 3a). Na safra 2004/2005, o Caiapó, embora tenha apresentado com baixas doses de $\mathrm{N}$ as mais elevadas produtividades, foi menos eficiente na resposta à utilização do nitrogênio que o IAC 202, o qual respondeu positivamente à adubação nitrogenada (Figura $3 \mathrm{~b}$ ). As menores produtividades foram obtidas com o Confiança, seguido por Primavera, os quais, embora tenham respondido positivamente ao $\mathrm{N}$ até as doses de 86 e $109 \mathrm{~kg} \mathrm{ha}^{-1}$ do nutriente (Figura $3 b$ ), tiveram reduzido número de panículas por área (Figura 1b). Stone et al. (1999), em quatro cultivares de arroz sob irrigação suplementar por aspersão, obtiveram resposta quadrática ao $\mathrm{N}$ com o máximo de produtividade de grãos com $113 \mathrm{~kg} \mathrm{ha}^{-1} \mathrm{de}$ N. Também Guimarães \& Stone (2003) e Buzetti et al. (2006), com cultivares de arroz de terras altas, observaram que a resposta ao $\mathrm{N}$ é dependente do cultivar, havendo aquelas com maior eficiência no uso do nutriente. Por sua vez, Mauad et al. (2003) verificaram que a aplicação de doses de $\mathrm{N}$ acima de $75 \mathrm{~kg}$ 
- Primavera $\mathrm{y}=1894+3,833 \mathrm{x}^{2}=0,98^{* *}$

- Carisma $y=2367+7,907 x R^{2}=0,99^{* *}$

\ IAC $202 \quad \mathrm{y}=2350+21,53 \mathrm{x}-0,103 \mathrm{x}^{2} \mathrm{R}^{2}=0,86^{* *}$

- Caiapó $\quad \mathrm{y}=1669+7,623 \times \mathrm{R}^{2}=0,94^{* *}$

$\times$ Confiança $y=3060^{\text {NS }}$

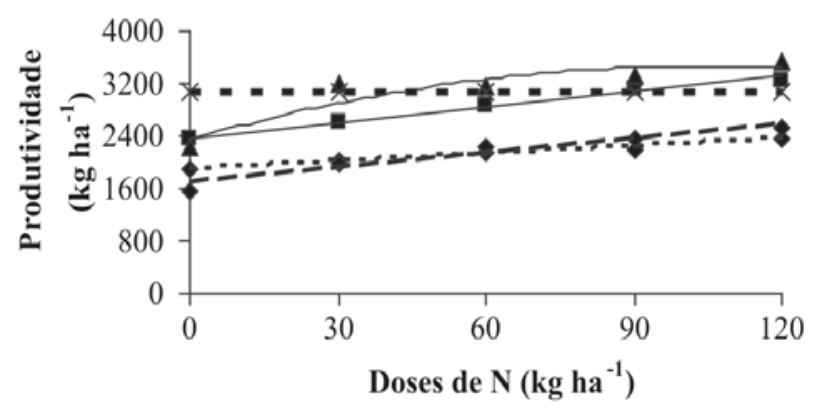

(a)

$$
\begin{array}{ll}
\text { - Primavera } & \mathrm{y}=1555+17,53 \mathrm{x}-0,0802 \mathrm{x}^{2} \mathrm{R}^{2}=0,955^{*} \\
\text { - Carisma } & \mathrm{y}=2118+21,84 \mathrm{x}-0,1202 \mathrm{x}^{2} \mathrm{R}^{2}=0,99 \\
\text { ( IAC 202 } & \mathrm{y}=2145+13,646 \mathrm{x} \mathrm{R}^{2}=0,93 \\
\text { - Caiapó } & \mathrm{y}=2874+6,4463 \mathrm{x} \mathrm{R}^{2}=0,87^{* *} \\
\text { × Confiança } & \mathrm{y}=1162+16,64 \mathrm{x}-0,097 \mathrm{x}^{2} \mathrm{R}^{2}=0,93^{* *}
\end{array}
$$

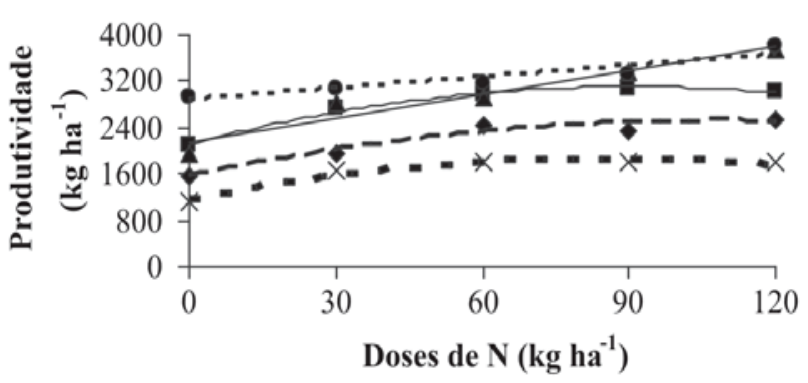

(b)
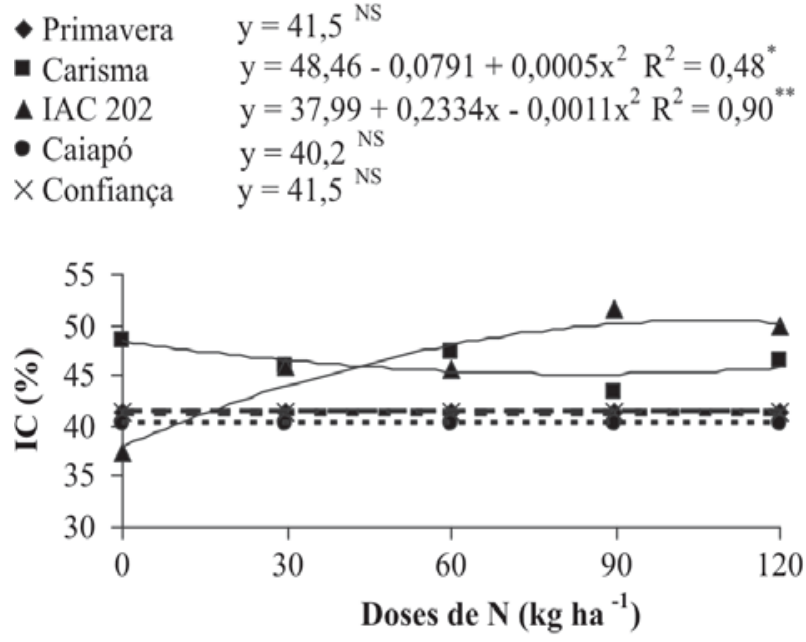

(c)

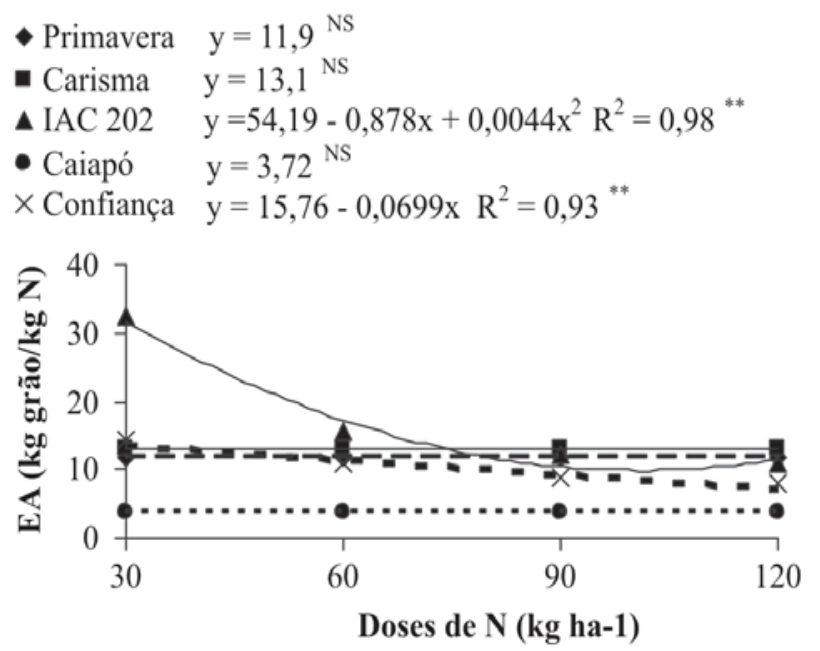

(e)
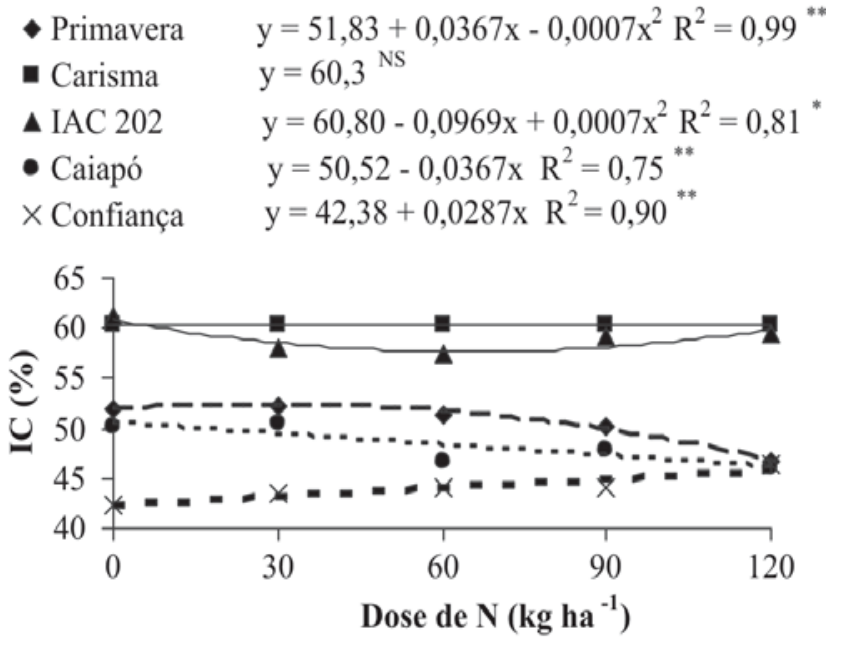

(d)

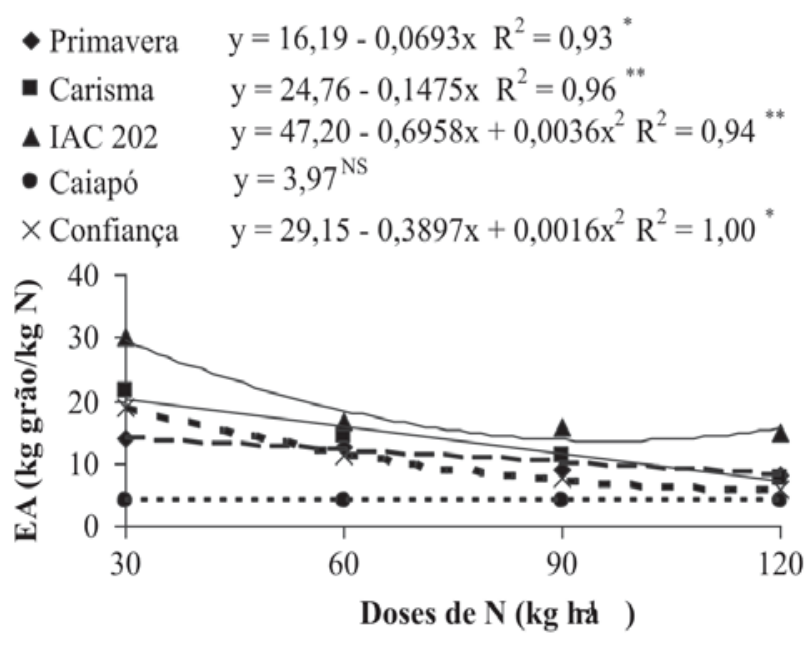

(f)

Figura 3. Efeito da interação entre os cultivares e as doses de nitrogênio em relação à produtividade de grãos (Figuras 3a - safra 2003/04 e 3b - safra 2004/05); índice de colheita (IC) - (Figuras 3c - safra 2003/04 e 3d - safra 2004/05) e eficiência agronômica de uso do N (EA) - (Figuras 3e - safra 2003/04 e 3f - safra 2004/05). 
Tabela 2. Valores médios referentes à massa de 100 grãos, produtividade de grãos e índice de colheita em diferentes cultivares de arroz submetidos à adubação nitrogenada em cobertura

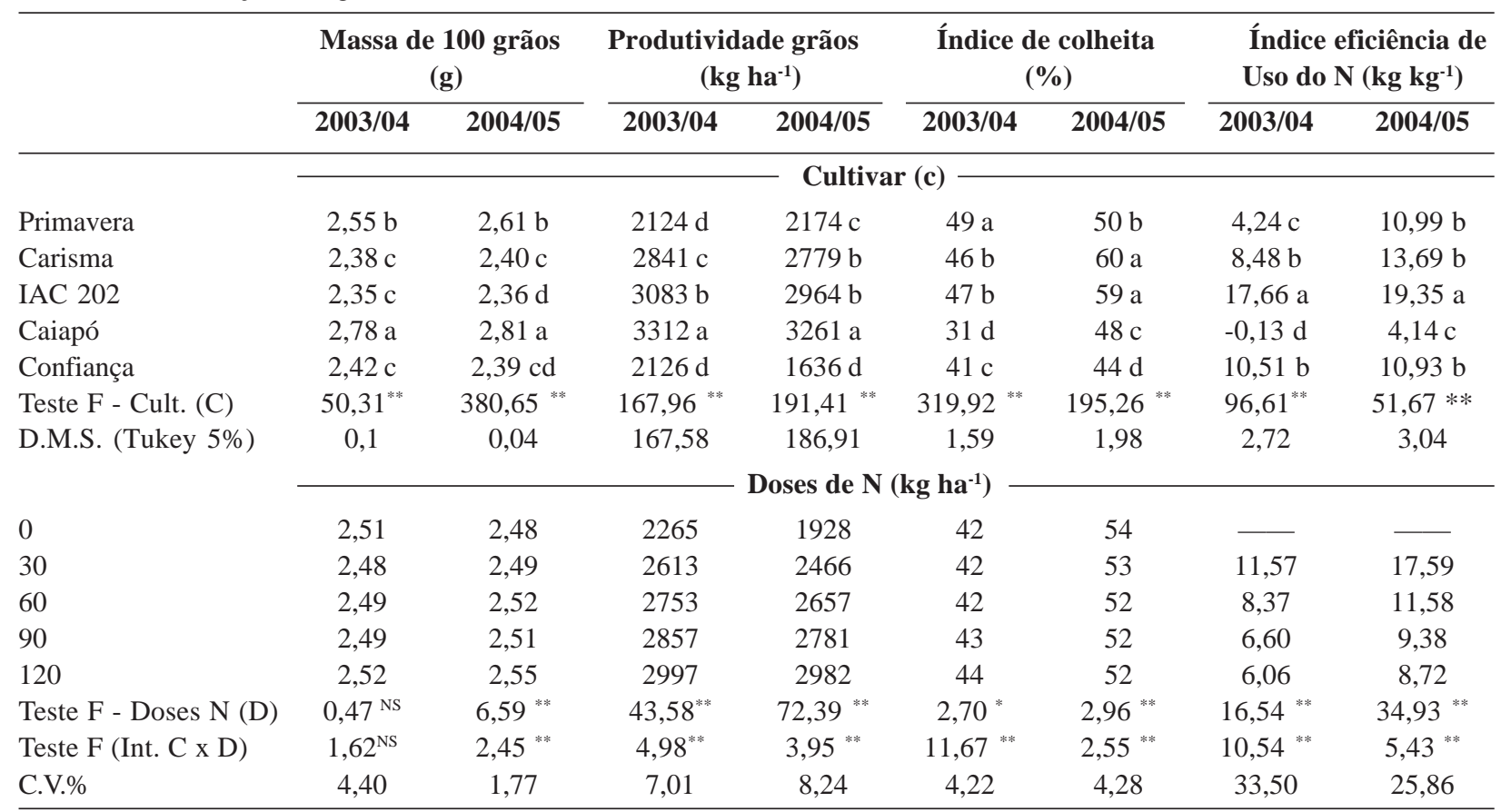

Médias seguidas da mesma letra na coluna não diferem entre si, pelo teste de Tukey, a 5\% de probabilidade.

** e $*=$ significativo a $1 \%$ e $5 \%$ de probabilidade pelo teste $\mathrm{F}$, respectivamente; NS = não-significativo.

ha-1 não interfere na produtividade de grãos. Os resultados obtidos demonstram que existe potencial de aumento da produtividade do arroz com a seleção de genótipos com maior potencial de produtividade e de absorção e utilização do N, o que está de acordo com Fageria \& Barbosa Filho (1982), Freitas et al. (2001) e Jiang et al. (2004).

Com relação ao índice de colheita (IC), foi observado efeito significativo para a interação entre cultivares e doses de $\mathrm{N}$ em ambos os anos agrícolas (Tabela 2). A adubação nitrogenada não interferiu nesse componente nos cultivares Primavera, Caiapó e Confiança na safra 2003/ 2004 (Figura 3c) e interferiu de forma diferenciada nos mesmos cultivares na safra 2004/2005 (Figura 3d), porém influenciou positivamente no IC do IAC 202 na safra 2003/ 2004, no qual, com $106 \mathrm{~kg} \mathrm{ha}^{-1}$ do nutriente, obteve-se valores de IC em torno de $50 \%$, o mesmo não ocorrendo na safra 2004/2005 (Figura 3d); para o cultivar Carisma houve com o uso do fertilizante nitrogenado tendência de redução nesse componente na safra 2003/2004 (Figura 3c). Cultivares com IC mais elevados são desejáveis, pois esse índice representa a eficiência de conversão de produtos sintetizados em material de importância econômica (grãos), sendo determinado tanto pelo genótipo como pela adubação nitrogenada e ano de cultivo (Fageria et al., 2007). Os cultivares Caiapó e Confiança apresentam menor IC (Tabela 2), o que pode ser comprovado na safra 2004/2005 em que esses cultivares, independentemente da dose de $\mathrm{N}$ utilizada, foram os menos eficientes na conversão da biomassa produtiva (Figura 3d).
No que diz respeito à eficiência agronômica do uso do $\mathrm{N}$ (EA), observa-se efeito significativo para interação entre cultivares e doses de N (Tabela 2). Nas duas safras, o cultivar Caiapó não respondeu ao fornecimento de $\mathrm{N}$ em cobertura, o mesmo ocorrendo com Primavera e Carisma na safra 2004/2005, com o IAC 202 destacando-se como o mais eficiente no uso do $\mathrm{N}$ fornecido nas duas safras (Figuras 3e e 3f), ou seja, embora o Caiapó se apresente como o mais produtivo entre os cultivares (Tabela 2) e em condições de ausência ou de reduzido fornecimento de $\mathrm{N}$ em cobertura (Figura 3b), o IAC 202 será aquele que, com o fornecimento de $\mathrm{N}$ em doses crescentes até $105 \mathrm{~kg} \mathrm{ha}^{-1}$ de $\mathrm{N}$ (Figura 3a), possibilitará maior EA no uso do $\mathrm{N}$ fornecido.

\section{CONCLUSÕES}

Dentre os cultivares testados, o Carisma apresenta o maior número de panículas por área, com reflexos na produtividade. O cultivar IAC 202 apresenta o maior número de espiguetas e de grãos por panícula.

A fertilidade das espiguetas diminui com o incremento da adubação nitrogenada.

Os cultivares Caiapó, IAC 202 e Carisma são os de maior produtividade, e o Primavera não responde ao incremento da adubação nitrogenada.

Os cultivares IAC 202 e Carisma possuem índice de colheita mais elevado e são mais responsivos ao nitrogênio aplicado em cobertura, sugerindo-se indicá-los para sistemas produtivos mais tecnificados. 
O cultivar Caiapó demonstra ser mais eficiente em absorver e utilizar o $\mathrm{N}$ contido no solo, sugerindo-se sua indicação para sistemas produtivos de menor aporte de tecnologia.

\section{REFERÊNCIAS}

Andrade WEB, Amorim Neto S, Fernandes GMB \& Oliveira HF (1992) Épocas de aplicação de nitrogênio em cultivares de arroz irrigado na região Norte Fluminense. Lavoura Arrozeira, 45:14-17.

Arf O, Rodrigues RAF, Crusciol CAC, Sá ME \& Buzetti S (2003) Soil management and nitrogen fertilization for sprinkler-irrigated upland rice cultivars. Scientia Agrícola, 60:345-352.

Arf O, Rodrigues RAF, Sá ME, Crusciol CAC \& Pereira JCR (2002) Preparo do solo, irrigação por aspersão e rendimento de engenho de arroz de terras altas. Scientia Agricola, 59:321-326.

Arf O, Sá ME, Buzzeti S, Rodrigues RAF, Stradioto MF \& Lima, FS (1996) Respostas da cultura do arroz para sequeiro com irrigação suplementar à aplicação de boro e zinco: produção de sementes. Científica, 24:135-148.

Buzetti S, Bazanini GC, Freitas JG, Andreotti M, Arf O \& Sá ME (2006) Meira, FA. Resposta de cultivares de arroz a doses de nitrogênio e do regulador de crescimento cloreto de clormequat. Pesquisa Agropecuária Brasileira, 41:1731-1737.

Cantarella H \& Furlani PR (1997) Recomendações de adubação e calagem de arroz de sequeiro para o Estado de São Paulo. In: RAIJ B van, Cantarella H, Quaggio JA, Furlani AMC (Eds) Recomendações de calagem e adubação para o Estado de São Paulo. 2. ed. rev. atual. Campinas, IAC. p.48-49. (Boletim Técnico, 100).

Donald CM \& Hamblim J (1976) The biological yield and harvest index of cereals as agronomic and plant breeding criteria. Advances in Agronomy, 28:361-405.

Fageria NK \& Barbosa Filho MP (1982) Avaliação preliminar de cultivares de arroz irrigado para a maior eficiência de utilização de nitrogênio. Pesquisa Agropecuária Brasileira, 17:1709-1712.

Fageria NK, Sant'ana EP, Castro EM \& Morais OP (1995a) Resposta diferencial de genótipos de arroz de sequeiro à fertilidade do solo. Revista Brasileira de Ciência do Solo, 19:261-267.

Fageria NK, Sant‘ana EP, Morais OP (1995b) Resposta de genótipos de arroz de sequeiro favorecido à fertilidade do solo. Pesquisa Agropecuária Brasileira, 30:1155-1161.

Fageria NK, Baligar VC \& Clark RB (2006) Physiology of crop production. New York, Haworth Press. 345p.

Fageria NK, Santos AB \& Cutrim VA (2007) Produtividade de arroz irrigado e eficiência de uso do nitrogênio influenciadas pela fertilização nitrogenada. Pesquisa Agropecuária Brasileira, 42:1029-1034.

Fornasieri Filho D \& Fornasieri JL (2006) Manual da cultura do arroz. Jaboticabal, FUNEP. 589p.

Freitas JG, Azzini LE, Cantarella H, Bastos CR, Castro LHSM, Gallo PB \& Felício JC (2001) Resposta de cultivares de arroz irrigado ao nitrogênio. Scientia Agricola, 58:573-579.

Freitas JG, Cantarella H, Salomon MV, Malavolta VMA, Castro LHSM, Gallo PB \& Azzini LE (2007) Produtividade de cultivares de arroz irrigado resultante da aplicação de doses de nitrogênio. Bragantia, 66:317-325.

Guimarães CM, Stone LF (2003) Adubação nitrogenada do arroz de terras altas no sistema de plantio direto. Revista Brasileira de Engenharia Agrícola e Ambiental, 7:210-214.
Jiang LG, Dai TB, Jiang D, Cao WK, Gan XQ \& Wei S (2004) Characterizing physiological N-use efficiency as influenced by nitrogen manegement in three rice cultivars. Field Crops Research, 88:239-250.

Lara Cabezas WAR, Korndofer GH \& Motta AS (1997) Volatilização de N-NH3 na cultura de milho: II. Avaliação de fontes sólidas e fluídas em sistema de plantio direto e convencional. Revista Brasileira de Ciência do Solo, 21:489-496.

Mauad M, Crusciol CAC, Grassi Filho H \& Corrêa JC (2003) Nitrogen and silicon fertilization of upland rice. Scientia Agricola,60:761-765.

Raij Bvan \& Quaggio JA (1983) Métodos de análise de solo para fins de fertilidade. Campinas, IAC. 31p. (Boletim técnico, B1).

Sims AL, Schepers JS, Olson RA, Power JF (1998) Irrigated corn yield and nitrogen accumulation response in a comparison of no-till and conventional till: tillage and surface-residue variables. Agronomy Journal, 90:630-637.

Stone LF, Silveira PM, Moreira JAA \& Yokoyama LP (1999) Adubação nitrogenada em arroz sob irrigação suplementar por aspersão. Pesquisa Agropecuária Brasileira, 34:927-932.

Stone LF \& Pinheiro BS (1998) O arroz sob irrigação suplementar por aspersão. In: Breseghello F, Stone LF. Tecnologia para o arroz de terras altas. Santo Antônio de Goiás, Embrapa Arroz e Feijão. 161p. 